\title{
THE MODIFIED PEAKEDNESS AS A $M|G| \infty$ BUSY CYCLE DISTRIBUTION CHARACTERIZING PARAMETER ${ }^{1}$
}

Prof. Dr. Manuel Alberto M. Ferreira

Instituto Universitário de Lisboa (ISCTE - IUL), BRU - IUL, Lisboa (PORTUGAL)

manuel.ferreira@iscte.pt

DOI: $10.7813 / 2075-4124.2013 / 5-2 / A .1$

\section{ABSTRACT}

It is exposed that a parameter, then called $\theta$,similar to the parameter $\eta$ proposed in (1) to characterize the $M|G| \infty$ queue busy period distribution, that is a modification of the peakedness proposed in (2) is also useful to characterize the $M / G / \infty$ queue busy cycle distribution.

Key words: $M|G|^{\infty}$, busy cycle, peakedness, $\theta$.

\section{INTRODUCTION}

In a $M|G|^{\infty}$ queue system, $\lambda$ is the Poisson process arrivals rate, $\alpha$ is the mean service time, $G($.$) is the$ service time distribution function and so $\alpha=\int_{0}^{\infty}[1-G(t)] d t$. The traffic intensity is defined as

$$
\rho=\lambda \alpha
$$

Upon its arrival a customer finds immediately an available server. And each customer service is independent from the other customers' services.

In the operation of this queue, as it happens with any other, there is a sequence of idle and busy periods. An idle period followed by a busy period is a busy cycle. Call $I, B$ and $Z$ the idle period, the busy period and the busy cycle, respectively, lengths random variables. Obviously,

$$
Z=I+B
$$

As $I$ and $B$ are independent, see (3), the following relation

$$
\bar{Z}(s)=\bar{I}(s) \bar{B}(s)
$$

among the respective Laplace transforms holds, where

$$
\bar{I}(s)=\frac{\lambda}{\lambda+s}
$$

since the idle period is exponentially distributed with parameter $\lambda$, as it happens with any queue with Poisson arrivals, and

$$
\bar{B}(s)=1+\frac{1}{\lambda}\left(s-\frac{1}{\int_{0}^{\infty} e^{-s t-\lambda-\int_{0}^{t}[1-G(v)] d v} d t}\right)
$$

The goal of this paper is to introduce a parameter, $\theta$, which is a modification of the peakedness, for the $Z$ random variable and show that it is useful to characterize the $Z$ distribution. In section 2 it is introduced the peakedness for the $M|G|^{\infty}$ queue system busy cycle distribution and studied its properties. Then, in section 3 , taking in account the study of section 2, it is introduced the modified peakedness for the $M|G| \infty$ queue system busy cycle distribution, which is thought as an improvement of the peakedness. The paper ends with the conclusions and a list of references.

\section{THE Z RANDOM VARIABLE PEAKEDNESS}

For the random variable $Z$, the peakedness, here called $q$, is given by, see (1),

$$
q=\bar{Z}(1 / \alpha)
$$

\footnotetext{
${ }^{1}$ This work was financially supported by FCT through the Strategic Project PEst-OE/EGE/UI0315/2011.
} 
and, being $p$ the peakedness for $B$, it holds

and, of course, $q \leq p$.

$$
q=\frac{\rho}{\rho+1} p
$$

It is easy to show that

$$
q=\sum_{n=0}^{\infty}(-1)^{n} \frac{E\left[Z^{n}\right]}{n ! \alpha^{n}}
$$

and so $q$ includes information of the $Z$ every order centered at the origin moments such as $p$ includes information of the $B$ every order centered at the origin moments.

For the collection of service times' distribution ${ }^{1}$, see (4),

$$
\begin{array}{r}
G(t)=1-\frac{\left(1-e^{-\rho}\right)(\lambda+\beta)}{\lambda e^{-\rho}\left(e^{(\lambda+\beta) t}-1\right)+\lambda}, t \geq 0,-\lambda \leq \beta \leq \frac{\lambda}{e^{\rho-1}} \\
q=\alpha \frac{e^{-\rho}(\lambda+\beta)(\rho+1)-\beta}{(\rho+1)\left(e^{-\rho}(\rho+\alpha \beta)+1\right)},-\lambda \leq \beta \leq \frac{\lambda}{e^{\rho-1}}
\end{array}
$$

and

$$
-\beta=-\lambda
$$

$$
q=0
$$

- $\beta=0\left(M\left|G_{1}\right|^{\infty}\right.$ system $)$

$$
q^{G_{1}}=\frac{\rho}{e^{\rho}+\rho}
$$

$-\beta=\frac{\lambda}{e^{\rho}-1}\left(M\left|G_{2}\right|^{\infty}\right.$ system $)$

For the systems:

$$
q^{G_{2}}=\frac{\rho^{2}}{e^{\rho}(\rho+1)+\rho^{2}-1}
$$

$-M|D| \infty$ (constant service times)

$-M|M| \infty$ (exponential service times)

$$
q^{D}=\frac{\rho}{e^{\rho+1}+\rho}
$$

$$
q^{M}=\frac{e^{\rho}-\rho-1}{(\rho+1)\left(e^{\rho}-1\right)}
$$

For the service times $G_{1}, G_{2}, D$ and $M, q$ depends only on $\rho$ and is given by very simple expressions. Except

$$
E[Z]=\frac{e^{\rho}}{\lambda}
$$

that depends on service time only by its mean $^{2}$, it is the only parameter with simple expression, for the distribution of $Z$, to the $M|M| \infty$ systems, confer with (6).

For service times distributions related with the exponential distribution, important in the reliability theory:

-If the service time distribution is NBUE-New Better than Used in Expectation with mean $\alpha$, $\int_{t}^{\infty}[1-G(v)] d v \geq \int_{t}^{\infty} e^{-\frac{v}{\alpha}} d v(7$, p. 273), and

$$
q^{N B U E} \leq \frac{e^{\rho}-\rho-1}{(\rho+1)\left(e^{\rho}-1\right)}
$$

-If the service time distribution is NWUE-New Worse than Used in Expectation with mean $\alpha$, $\int_{t}^{\infty}[1-G(v)] d v \leq \int_{t}^{\infty} e^{-\frac{v}{\alpha}} d v(7$, p. 273$)$, and

$$
q^{N W U E} \geq \frac{e^{\rho}-\rho-1}{(\rho+1)\left(e^{\rho}-1\right)}
$$

In general, if $G($.$) and H($.$) are service times distributions functions such that 1-G(t) \leq 1-H(t)$

$$
q^{G} \geq q^{H}
$$

\footnotetext{
${ }^{1}$ In this case the distribution function of $Z$ is a mixture of exponentials, see (5): $P(Z \leq t)=1-\frac{\left(1-e^{-\rho}\right)(\lambda+\beta)}{\lambda-e^{-\rho}(\lambda+\beta)} e^{-e^{-\rho}(\lambda+\beta) t}+\frac{\beta}{\lambda-e^{-\rho}(\lambda+\beta)} e^{-\lambda t}, t \geq 0,-\lambda \leq \beta \leq \frac{\lambda}{e^{\rho-1}}$

${ }^{2}$ It is usual to say that it is "insensible" to the service time distribution.
} 


\section{THE PARAMETER $\theta$}

The modified peakedness for Z, called $\theta$ is given by, see (1), $\theta=\frac{q-\left(1-\frac{e^{\rho}}{\rho}\right)}{\frac{e^{\rho}}{\rho}-1}$, that is

$$
\theta=q \frac{\rho}{e^{\rho}-\rho}+1
$$

It was taken out of $q$ the parts that do not depend on the service time's distribution form, check with the expression (2.3), and then it was standardized dividing by the common part.

After what was seen in the former section, it is possible to obtain simple expressions for $\theta^{G_{1}}, \theta^{G_{2}}, \theta^{D}$ and $\theta^{M}$ depending only on $\rho$. And evidently the properties of $q$ extend to $\theta$. It is easy to show that

$$
1 \leq \theta \leq \frac{\rho^{2}}{\left(e^{\rho}+1\right)\left(e^{\rho}-\rho\right)}+1
$$

for any service time distribution, concluding so that

$$
\lim _{\rho \rightarrow \infty} \theta=1
$$

Computing $\theta$ for some service times distributions, taking various values of $\rho$, were obtained the values presented in Table 1. In it $P$ means the power distribution with parameter ${ }^{1} c=.5$.

Table 1. Values of $\theta$ for some service times distribution functions

\begin{tabular}{ccccccc}
\hline $\mathbf{G}$ & $\boldsymbol{\rho}=\mathbf{5}$ & $\boldsymbol{\rho}=\mathbf{1}$ & $\boldsymbol{\rho}=\mathbf{5}$ & $\boldsymbol{\rho}=\mathbf{1 0}$ & $\boldsymbol{\rho}=\mathbf{1 5}$ & $\boldsymbol{\rho}=\mathbf{2 0}$ \\
\hline $\mathbf{G}_{1}$ & 1.0573588 & 1.0841882 & 1.0000456 & 1.0000000 & 1.0000000 & 1.0000000 \\
$\mathbf{G}_{2}$ & 1.0357639 & 1.0575796 & 1.0000383 & 1.0000000 & 1.0000000 & 1.0000000 \\
$\mathbf{D}$ & 1.0247402 & 1.0373147 & 1.0000171 & 1.0000000 & 1.0000000 & 1.0000000 \\
$\boldsymbol{M}$ & 1.0376733 & 1.0654280 & 1.0002254 & 1.0000000 & 1.0000000 & 1.0000000 \\
$\boldsymbol{P}$ & 1.0359789 & 1.0646113 & 1.0004005 & 1.0000001 & 1.0000000 & 1.0000000 \\
\hline
\end{tabular}

For this service time distribution $\theta^{P}$ was computed directly from (2.1) and (3.1).

When $\rho$ assumes great values: above $\rho=10$ for some service times distributions and $\rho=20$ for others, under some conditions, the busy period is practically exponentially distributed $(8,9)$. In the same conditions $\theta$ is practically 1 .

It is interesting to compare the values of $\theta$, in Table 1, with the values of $\eta$, in Table 2, got from (1), computed in the same conditions, being the most relevant

Table 2. Values of $\eta$ for some service times distribution functions

\begin{tabular}{ccccccc}
\hline $\boldsymbol{G}$ & $\boldsymbol{\rho}=\mathbf{5}$ & $\boldsymbol{\rho = 1}$ & $\boldsymbol{\rho}=\mathbf{5}$ & $\boldsymbol{\rho = 1 0}$ & $\boldsymbol{\rho = 1 5}$ & $\boldsymbol{\rho}=\mathbf{2 0}$ \\
\hline $\mathbf{G}_{1}$ & 3.3469730 & 1.7488465 & 1.0013731 & 1.0000002 & 1.0000000 & 1.0000000 \\
$\mathbf{G}_{\mathbf{2}}$ & 2.4633636 & 1.5121659 & 1.0011518 & 1.0000002 & 1.0000000 & 1.0000000 \\
$\boldsymbol{D}$ & 2.0123054 & 1.3319113 & 1.0005158 & 1.0000001 & 1.0000000 & 1.0000000 \\
$\boldsymbol{M}$ & 2.5414941 & 1.5819767 & 1.0067837 & 1.0000454 & 1.0000000 & 1.0000000 \\
$\boldsymbol{P}$ & 2.4721612 & 1.5747122 & 1.0120525 & 1.0001526 & 1.0000000 & 1.0000000 \\
\hline
\end{tabular}

to note that $\eta \geq \theta$, being the major differences for the lowest traffic intensities.

\section{CONCLUSIONS}

The parameter $\theta$, defined in Expression (3.1), incorporates information on the whole moments of $Z$ centered at the origin.

It assumes different values when the distributions of $Z$ differ as functions of the service distribution.

And there are simple bounds for $\theta$ depending only on the traffic intensity $\rho$.

Even for the $M|M| \infty$ system, with analytically intractable parameters in the case of the distribution of $Z, \theta$ is written in a quite simple expression. This queue system, very important from the applications point of view, see (10-16), is a quite strange case because not even its markovian properties, owing to the exponential inter-arrival times and services, brings the expectable analytical simplicity.

It is even admissible that close values of $\theta$, for different service time's distributions, indicate resemblance of the respective $Z$ distributions behaviors.

So $\theta$ is a parameter that can help to characterize the distribution of $Z$, discriminating among different service time distributions.

This parameter, $\theta$, may be included in the class of other composite parameters, as for instance the kurtosis or the skewness, see (17), that are used to characterize probability distributions putting an emphasis in their

$$
{ }^{1} \alpha=\frac{c}{c+1} \text {. }
$$


probability functions or probability density functions graphic characteristics. But it is more complete and complex than any of the two examples here called, since incorporates the whole distribution centered at the origin moments. Because of that, its interpretation in probability functions or probability density functions graphic characteristics terms is not so obvious and it is an interesting open field of investigation.

\section{REFERENCES}

1. M.A.M. Ferreira. A $M|G| \infty$ queue busy period distribution characterizing parameter. Computer and Information Science, 6 (1), 83-88, 2013. http://dx.doi.org/10.5539/cis.v6n1p83

2. W. Whitt. On approximations for queues, I: extremal distributions. A T \&T Bell Laboratories Technical Journal, 63(1), 115-138, 1984.

3. L. Tackács. An introduction to queueing theory. Oxford University Press, New York, 1962.

4. M.A.M. Ferreira. Application of Riccati equation to the busy period study of the $M|G| \infty$ system. Statistical Review, $1^{\text {st }}$ Quadrimester, INE, 23-28, 1998.

5. M.A.M. Ferreira, M. Andrade. Looking to a $M|G| \infty$ system occupation through a Riccati equation. Journal of Mathematics and Technology, 1 (2), 58-62, 2010.

6. M.A.M. Ferreira, M. Andrade, J. A. Filipe. The age or excess of the $M / G / \infty$ queue busy cycle mean value. Computer and Information Science, 5(5), 93-97, 2012. http://dx.doi.org/10.5539/cis.v5n5p93

7. S. Ross. Stochastic Processes. Wiley, New York, 1983.

8. M.A.M. Ferreira. $M|G| \infty$ queue heavy-traffic situation busy period length distribution (power and Pareto service distributions). Statistical Review, $1^{\text {st }}$ Quadrimester, INE, 27-36, 2001.

9. M.A.M. Ferreira. The exponentiality of the $M|G|^{\infty}$ queue busy period. Actas das XII Jornadas LusoEspanholas de Gestão Científica, Volume VIII-Economia da Empresa e Matemática Aplicada. UBI, Covilhã, Portugal, 267-272, 2002.

10. J. Figueira, M.A.M. Ferreira. Representation of a pensions fund by a stochastic network with two nodes: an exercise. Portuguese Revue of Financial Markets, 1(3), 1999.

11. J.C. Hershey, E. N. Weiss, A. C. Morris. A stochastic service network model with application to hospital facilities. Operations Research, 29(1), 1-22, 1981. http://dx.doi.org/10.1287/opre.29.1.1.

12. L. Kleinrock. Queueing systems. Vol. I and Vol. II. Wiley- New York, 1985.

13. M.J. Carrillo. Extensions of Palm's theorem: a review. Management Science, 37(6), 739-744, 1991. http://dx.doi.org/10.1287/mnsc.37.6.739.

14. M.A.M. Ferreira, M. Andrade, J.A. Filipe. Networks of queues with infinite servers in each node applied to the management of a two echelons repair system. China-USA Business Review, 8(8), 39-45 and 62, 2009.

15. R. Syski. Introduction to congestion theory in telephone systems. Oliver and Boyd- London, 1960.

16. R. Syski. Introduction to congestion theory in telephone systems. North Holland, Amsterdam, 1986.

17. M. G. Kendall and A. Stuart: The advanced theory of statistics. Distributions theory. London, Charles Griffin and Co., Ltd. $4^{\text {th }}$ Edition, 1979.

18. M. Andrade. A note on foundations of probability. Journal of Mathematics and Technology, 1(1), 96-98, 2010.

19. M.A.M. Ferreira. Computational simulation of infinite servers systems. Statistical Review, $3^{\text {rd }}$ Quadrimester, INE, 23-28, 1998.

20. M.A.M. Ferreira. Differential equations important in the $M|G| \infty$ queue system transient behavior and busy period study. Proceedings of 4th International Conference APLIMAT 2005, Bratislava, Slovakia, 119-132, 2005.

21. M.A.M. Ferreira, M. Andrade. The ties between the $M|G| \infty$ queue system transient behavior and the busy period. International Journal of Academic Research, 1(1), 84-92, 2009.

22. M.A.M. Ferreira, M. Andrade. $M|G| \infty$ system transient behavior with time origin at the beginning of a busy period mean and variance. APLIMAT-Journal of Applied Mathematics, 3(3), 213-221, 2010.

23. M.A.M. Ferreira, M. Andrade. Fundaments of theory of queues. International Journal of Academic Research, 3(1), part II, 427-429, 2011.

24. M.A.M. Ferreira, M. Andrade. Busy period and busy cycle distributions and parameters for a particular $M|G|^{\infty}$ queue system. American Journal of Mathematics and Statistics, 2(2), 10-15, 2012. http://article.sapub.org/10.5923.j.ajms.20120202.03.html.http://dx.doi.org/10.5923/j.ajms.20120202.03.

25. M.A.M. Ferreira, M. Andrade. Queue networks models with more general arrival rates. International Journal of Academic Research, 4(1), part A, 5-11, 2012.

26. M.A.M. Ferreira, M. Andrade. Transient behavior of the $M|G| \mathrm{m}$ and $M|G| \infty$ system. International Journal of Academic Research, 4(3), part A, 24-33, 2012.

27. M.A.M. Ferreira, M.F. Ramalhoto. Estudo dos parâmetros básicos do período de ocupação da fila de espera $M|G|^{\infty}$. A Estatística e o Futuro e o Futuro da Estatística. Actas do I Congresso Anual da S.P.E., Edições Salamandra, Lisboa, 1994.

28. M.F. Ramalhoto, M. A. M. Ferreira. Some further properties of the busy period of an M $|\mathrm{G}| \infty$ queue. Central European Journal of Operations Research and Economics, 4(4), 251-278, 1996.

29. W. Stadje. The busy period of the queueing system M $|\mathrm{G}| \infty$. Journal of Applied Probability, 22, 697704, 1985. http://dx.doi.org/10.2307/3213872. 
Copyright of International Journal of Academic Research is the property of International Journal of Academic Research and its content may not be copied or emailed to multiple sites or posted to a listserv without the copyright holder's express written permission. However, users may print, download, or email articles for individual use. 
Copyright of International Journal of Academic Research is the property of International Journal of Academic Research and its content may not be copied or emailed to multiple sites or posted to a listserv without the copyright holder's express written permission. However, users may print, download, or email articles for individual use. 